\title{
PROCEDIMENTOS PARA O ARMAZENAMENTO DE SEMENTES DE Poncirus trifoliata (L.) Raf. ${ }^{1}$
}

\author{
ROBERTO PEDROSO DE OLIVEIRA², WALKYRIA BUENO SCIVITTARO ${ }^{3}$, ELIZETE BEATRIZ RADMANN ${ }^{4}$
}

\begin{abstract}
RESUMO - Objetivou-se estabelecer uma metodologia para o armazenamento de sementes de Poncirus trifoliata, que é o principal porta-enxerto de citros utilizado no Rio Grande do Sul. Foram avaliados os efeitos de dois pré-tratamentos: a) químico - Benomyl (1,5 g i.a kg-1 de sementes); b) térmico-químico - imersão em água a $52^{\circ} \mathrm{C}$, por 10 minutos, seguida da aplicação de Benomyl (1,5 g i.a $\mathrm{kg}^{-1}$ de sementes). As condições de armazenamento estudadas foram: a) ambiente - estocagem em sala escura sob condições de temperatura e de umidade relativa do ar não controladas; b) geladeira - temperatura de $8^{\circ} \mathrm{C}$ e umidade relativa do ar de $60 \%$; c) dessecador - temperatura não controlada e umidade relativa do ar de $16 \%$; d) dessecador em geladeira - temperatura de $8^{\circ} \mathrm{C}$ e umidade relativa do ar de $16 \%$; e) câmara fria - temperatura de $4^{\circ} \mathrm{C}$ e umidade relativa do ar de $70^{\circ}$. Verificou-se que as sementes de 'Trifoliata' são recalcitrantes, sendo bastante sensíveis ao armazenamento. Não houve efeito dos pré-tratamentos na conservação das sementes. A melhor condição de armazenamento foi em câmara fria, permitindo manter o poder germinativo das sementes em $57,1 \%$ aos 150 dias.
\end{abstract}

Termos para indexação: câmara fria, dessecador, geladeira, porta-enxerto, tratamento químico, tratamento térmico

\section{METHODOLOGY FOR SEED STORAGE OF Poncirus trifoliata (L.) Raf.}

ABSTRACT - The aim of this work was to establish a methodology for seed storage of Poncirus trifoliata, that is the main citrus rootstock in Rio Grande do Sul. The pre-treatments evaluated were: a) chemical - Benomyl (1,5 g a.i. $\mathrm{kg}^{-1}$ of seeds); b) thermal/chemical - water immersion at $52^{\circ} \mathrm{C}$ for 10 minutes, following application of Benomyl (1,5 g a.i. $\mathrm{kg}^{-1}$ of seeds). The storage conditions were: a) environment - storage in dark room under not controlled temperature and air moisture; b) Refrigerator $-8^{\circ} \mathrm{C}$ and $60 \%$ of air moisture; c) dissector - not controlled temperature and $16 \%$ of air moisture; d) dissector in refrigerator $-8^{\circ} \mathrm{C}$ and $16 \%$ of air moisture; e) Cold chamber $-4^{\circ} \mathrm{C}$ and $70 \%$ of air moisture. The 'Trifoliata' seeds are recalcitrants, because they are highly sensible to storage. It was not observed effect of pre-treatments for seed conservation. The storage in cold chamber was the best treatment, maintaining $57,1 \%$ of seed viability during 150 days.

Index terms: cold chamber, dissector, refrigerator, rootstock, chemical treatment, thermal treatment

\section{INTRODUÇÃO}

Frutas cítricas para o consumo in natura têm sido demandadas em diversos países, inclusive no Brasil (Agrianual, 2003). O Estado do Rio Grande do Sul dispõe de extensas áreas com condições de solo e de clima propícias à citricultura e potencialmente adequadas para a produção de frutos com a coloração acentuada exigida pelo mercado (Oliveira et al., 2001). Em decorrência disso, vários programas governamentais têm sido implementados no Estado para fomentar o desenvolvimento dessa alternativa agrícola.

Atualmente, a legislação do Rio Grande do Sul exige que as mudas certificadas de citros sejam produzidas em ambientes protegidos contra vetores de doenças (Secretaria da Agricultura e do Abastecimento, 1998), denominados de viveiros-telado. Para maximizar a utilização da infra-estrutura dos viveiros é necessário dispor-se de metodologia que possibilite a conservação das sementes dos porta-enxertos, permitindo a realização de semeaduras durante todo o ano e reduzindo as perdas de sementes, as quais apresentam um custo elevado.

O 'Trifoliata' [Poncirus trifoliata (L.) Raf.] é o principal portaenxerto utilizado no Rio Grande do Sul, principalmente por sua maior tolerância ao frio e por conferir alta qualidade à fruta (Oliveira et al., 2001). Além disso, é resistente à gomose de Phytophthora e ao vírus da tristeza, muito embora seja suscetível ao viróide do exocorte e à clorose de ferro em solos calcários e com $\mathrm{pH}$ igual ou superior a neutralidade (Castle, 1987).

As sementes de 'Trifoliata' e de seus híbridos são mais sensíveis ao armazenamento do que a dos demais porta-enxertos utilizados na produção de mudas de citros (Mumford \& Panggabean, 1982; Saipari et al., 1998), podendo ser consideradas recalcitrantes. Normalmente, quando armazenadas sob condições naturais, apresentam uma perda significativa do poder germinativo em poucos dias (Button et al., 1971).
Diversos métodos têm sido propostos para o armazenamento de sementes de 'Trifoliata', destacando-se o tratamento físico com água quente, a secagem, o tratamento químico com fungicidas e a redução da temperatura do ambiente de estocagem (Koller et al., 1993). Esses fundamentam-se na redução da atividade metabólica da semente e da velocidade de multiplicação dos microrganismos contaminantes (Barbedo \& Bilia, 1998). A despeito de já se dispor de informações sobre o assunto, muitas dúvidas persistem sobre os procedimentos mais adequados para a conservação das sementes por um período prolongado.

Este trabalho teve por objetivo estabelecer uma metodologia eficiente, prática e econômica para a conservação de sementes do portaenxerto 'Trifoliata'.

\section{MATERIAL EMÉTODOS}

O experimento foi realizado, sob condições de laboratório, no período de abril a dezembro de 2002, em Pelotas, RS. As sementes de Poncirus trifoliata (L.) Raf. seleção Davis A foram removidas de frutos completamente maduros, colhidos no final do mês de março do mesmo ano. A remoção da muscilagem foi realizada manualmente, por meio da lavagem das sementes com água corrente. Após, essas foram secas à sombra, sobre papel-toalha, por 72 horas.

Na seqüência, aplicaram-se às sementes dois pré-tratamentos: a) químico, que consistiu na aplicação de Benomyl, na concentração de $1,5 \mathrm{~g}$ i.a kg-1 de sementes; b) térmico-químico, compreendendo a imersão das sementes em água a $52^{\circ} \mathrm{C}$, por 10 minutos, sob agitação constante, seguida da aplicação de Benomyl, em concentração igual a do tratamento anterior. As sementes oriundas de ambos os pré-tratamentos foram selecionadas, eliminando-se as aparentemente mal formadas e as danificadas, distribuídas em grupos de 10 e acondicionadas em sacos de papel manteiga $(10 \mathrm{~cm} \times 10 \mathrm{~cm})$.

\footnotetext{
(Trabalho 055/2003). Recebido: 31/03/2003. Aceito para publicação: 01/10/2003. Financiado pelo MAPA e CNPq.

${ }^{2}$ Eng. Agr., D.S., Pesquisador da Embrapa Clima Temperado, Cx.P. 406, 96001-970, Pelotas, RS. Bolsista do CNPq. Tel. (53) 275 8100. E-mail: rpedroso@cpact.embrapa.br.

${ }^{3}$ Eng. Agr., D.S., Pesquisador da Embrapa Clima Temperado. Tel. (53) 275 8100. E-mail: wbscivit@cpact.embrapa.br.

${ }^{4}$ Bolsista DTI do CNPq. Tel. (53) 275 8100. E-mail: eradmann@hotmail.com.
} 
Após, procedeu-se ao armazenamento das sementes, que variou quanto às condições de temperatura e de umidade relativa do ar, segundo os tratamentos: a) ambiente - estocagem em sala escura sob condições de temperatura e de umidade relativa do ar não controladas; b) geladeira - temperatura de $8^{\circ} \mathrm{C}$ e umidade relativa do ar de $60 \%$; c) dessecador - temperatura não controlada e umidade relativa do ar de $16 \%$; d) dessecador em geladeira - temperatura de $8^{\circ} \mathrm{C}$ e umidade relativa do ar de $16 \%$; e) câmara fria - temperatura de $4^{\circ} \mathrm{C}$ e umidade relativa do ar de $70 \%$.

No tempo zero e a cada 30 dias, durante oito meses, foram realizados testes de germinação das sementes. Para tanto, inicialmente, removeu-se de forma manual o tegumento das sementes, sendo, cada grupo de 10 sementes, disposto em saco plástico transparente com dimensões de $10 \mathrm{~cm} \mathrm{x} 12 \mathrm{~cm}$, contendo papel de filtro esterilizado em autoclave. Este foi umedecido com água destilada previamente esterilizada. Em seguida, as sementes, nos respectivos sacos plásticos, foram colocadas em câmara de germinação a $25^{\circ} \mathrm{C}$, na ausência de luz. $\mathrm{O}$ porcentual de germinação foi avaliado, semanalmente, durante 40 dias, considerando-se germinada as plântulas com desenvolvimento da parte aérea e sistema radicular.

Os tratamentos foram dispostos em delineamento inteiramente ao acaso em parcelas subdivididas com três repetições, considerandose como parcelas as combinações dos fatores pré-tratamento e condições de armazenamento das sementes e como subparcelas, o tempo de armazenamento destas. As unidades experimentais foram constituídas por grupos de 10 sementes, dispostas em sacos de papel manteiga. Para a análise de variância, os dados foram transformados para arco seno de $(\mathrm{X} / 100)^{1 / 2}$

\section{RESULTADOS E DISCUSSÃO}

Independentemente do tempo e das condições de armazenamento das sementes de 'Trifoliata', a germinação ocorreu, em sua maioria, do quinto ao trigésimo dia após o início do teste de germinação.

Sob condições de temperatura e umidade do ar não controladas, as sementes de 'Trifoliata' apresentaram perda da viabilidade após 30 dias de armazenamento. Button et al. (1971) também haviam verificado este fato após 28 dias e, por isso, as sementes desse cultivar podem ser classificadas como recalcitrantes.

No presente trabalho, não houve efeito significativo do prétratamento das sementes na porcentagem de germinação, ao longo do tempo de armazenamento (Tabela 1), sendo, portanto, desnecessário o emprego da imersão das sementes em água a $52^{\circ} \mathrm{C}$ por 10 minutos. $\mathrm{O}$ uso exclusivo do tratamento químico foi suficiente para controlar o desenvolvimento de microrganismos. Também não se verificou dormência das sementes de 'Trifoliata', para a qual o tratamento térmico teria importância (Koller et al., 1993).

Os resultados da análise de variância indicaram efeito significativo para os fatores tempo e condições de armazenamento. Conforme esperado, quanto maior o tempo de armazenamento, menor a viabilidade das sementes. $\mathrm{O}$ armazenamento em câmara fria foi o método mais eficiente na conservação das sementes de 'Trifoliata' (Tabela 2). Independentemente do tempo de armazenamento, obteve-se uma porcentagem média de $47,9 \%$ de germinação, por volta de nove vezes maior do que quando armazenada em geladeira. Além disso, foi o tratamento que possibilitou o maior tempo de armazenamento, sendo este de sete meses (Koller et al., 1993).

Em função dos resultados obtidos, observa-se que a redução da temperatura do ambiente de conservação é um dos fatores determinantes na conservação das sementes. Isto ocorre por proporcionar diminuição da atividade metabólica que se processa na semente e da velocidade de multiplicação de microrganismos. Platt \& Opitz (1973), Eshuys (1974) e Mumford \& Panggabean (1982) já haviam recomendado o uso de temperaturas de $2^{\circ} \mathrm{C}$ a $7^{\circ} \mathrm{C}$ para conservação de sementes de 'Trifoliata'. Koller et al. (1993) conseguiram conservar sementes de 'Trifoliata', com germinação entre $75 \%$ e $80 \%$, por um período de até um ano, sob temperaturas de $2^{\circ} \mathrm{C}$ a $5^{\circ} \mathrm{C}$.

Outro fator fundamental para a conservação de sementes de 'Trifoliata' consiste no nível de umidade do ar existente no ambiente de armazenamento (Koller et al. 1993). Por isso, são observadas diferenças significativas em experimentos de vários autores, utilizando mesma temperatura. Segundo Saipari et al. (1998), as sementes de 'Trifoliata' apresentam, em média, $52 \%$ de umidade no momento da colheita e $25 \%$ após a secagem ao ar. Estas são tão recalcitrantes, que Mumford \& Panggabean (1982) observaram perda de 5\% do poder germinativo simplesmente em decorrência do processo de secagem ao ar.

No presente trabalho, as sementes sempre foram mantidas em saquinhos que permitiram trocas de umidade da semente com o ambiente em que foram armazenadas. Portanto, o armazenamento em geladeira e câmara fria foi realizado em alta umidade, respectivamente a $60 \%$ e $70 \%$, enquanto que em dessecador, em baixa umidade (16\%). A perda completa do poder germinativo das sementes armazenadas em dessecador em apenas 30 dias (Tabela 2) pode ser atribuída à sensibilidade das sementes de 'Trifoliata' à diminuição da umidade. Saipari et al. (1998) também observaram perda do poder germinativo de sementes desse cultivar ao

TABELA 1 - Porcentagem de germinação de sementes do porta-enxerto Poncirus trifoliata (L.) Raf. seleção Davis A em função do pré-tratamento e do tempo de armazenamento. Pelotas, RS.

\begin{tabular}{|c|c|c|c|c|c|c|c|c|c|c|}
\hline \multirow[t]{2}{*}{ Pré-tratamento } & \multicolumn{10}{|c|}{ Tempo de armazenamento, dias } \\
\hline & 0 & 30 & 60 & 90 & 120 & 150 & 180 & 210 & 240 & Média \\
\hline Térmico/Químico & $97,6 \mathrm{a}^{1}$ & $11,2 \mathrm{~b}$ & $2,7 \mathrm{a}$ & $3,1 \mathrm{a}$ & $2,7 \mathrm{a}$ & $3,2 \mathrm{a}$ & $1,6 \mathrm{a}$ & $0,0 \mathrm{a}$ & $0,0 \mathrm{a}$ & $8,1 \mathrm{a}$ \\
\hline Químico & $93,3 \mathrm{~b}$ & $23,8 \mathrm{a}$ & $5,2 \mathrm{a}$ & $2,5 \mathrm{a}$ & $3,4 \mathrm{a}$ & $2,7 \mathrm{a}$ & $1,4 \mathrm{a}$ & $1,1 \mathrm{a}$ & $0,0 \mathrm{a}$ & $9,2 \mathrm{a}$ \\
\hline
\end{tabular}

'Para a análise de variância, os dados foram transformados para arco seno de $(\mathrm{X} / 100)^{1 / 2}$.

Médias seguidas de mesma letra nas colunas não diferem significativamente entre si pelo teste de Duncan (5\%).

TABELA 2 - Porcentagem de germinação de sementes do porta-enxerto Poncirus trifoliata (L.) Raf. seleção Davis A em função das condições e do tempo de armazenamento. Pelotas, RS.

\begin{tabular}{|c|c|c|c|c|c|c|c|c|c|c|}
\hline \multirow{2}{*}{$\begin{array}{l}\text { Condições de } \\
\text { armazenagem }\end{array}$} & \multicolumn{10}{|c|}{ Tempo de armazenamento, dias } \\
\hline & 0 & 30 & 60 & 90 & 120 & 150 & 180 & 210 & 240 & Média \\
\hline Câmara fria & $95,7 \mathrm{a}$ & $82,2 \mathrm{a}$ & $60,2 \mathrm{a}$ & $55,2 \mathrm{a}$ & $58,5 \mathrm{a}$ & $57,1 \mathrm{a}$ & $32,9 \mathrm{a}$ & $9,8 \mathrm{a}$ & $0 \mathrm{a}$ & $47,9 \mathrm{a}$ \\
\hline Geladeira & $95,7 \mathrm{a}$ & $42,3 \mathrm{~b}$ & $0,9 \mathrm{~b}$ & $0 \mathrm{~b}$ & $0 \mathrm{~b}$ & $0 \mathrm{~b}$ & $0 \mathrm{~b}$ & $0 \mathrm{~b}$ & $0 \mathrm{a}$ & $5,2 \mathrm{~b}$ \\
\hline Dessec./Gelad. & $95,7 \mathrm{a}$ & $7,7 \mathrm{c}$ & $0 \mathrm{~b}$ & $0 \mathrm{~b}$ & $0 \mathrm{~b}$ & $0 \mathrm{~b}$ & $0 \mathrm{~b}$ & $0 \mathrm{~b}$ & $0 \mathrm{a}$ & $3,9 \mathrm{bc}$ \\
\hline Dessecador & $95,7 \mathrm{a}$ & $0 \mathrm{~d}$ & $0 \mathrm{~b}$ & $0 \mathrm{~b}$ & $0 \mathrm{~b}$ & $0 \mathrm{~b}$ & $0 \mathrm{~b}$ & $0 \mathrm{~b}$ & $0 \mathrm{a}$ & $2,3 \mathrm{c}$ \\
\hline Ambiente & $95,7 \mathrm{a}$ & $0 \mathrm{~d}$ & $0 \mathrm{~b}$ & $0 \mathrm{~b}$ & $0 \mathrm{~b}$ & $0 \mathrm{~b}$ & $0 \mathrm{~b}$ & $0 \mathrm{~b}$ & $0 \mathrm{a}$ & $2,3 \mathrm{c}$ \\
\hline
\end{tabular}

${ }^{1}$ Para a análise de variância, os dados foram transformados para arco seno de $(\mathrm{X} / 100)^{1 / 2}$.

Médias seguidas de mesma letra nas colunas não diferem significativamente entre si pelo teste de Duncan (5\%). 
serem secas em ambiente com sílica a 9\% de umidade relativa do ar. Segundo Nakagawa \& Honjo (1979), as sementes de 'Trifoliata' somente germinam quando mantidas a uma umidade superior a $20 \%$, sendo ideal secar as sementes até $28 \%$ (Koller et al., 1993). Outros porta-enxertos de citros, com sementes menos recalcitrantes, como os limoeiros verdadeiros, o 'Cravo', o 'Galego' e o 'Rugoso Nacional' apresentam tolerância para menor umidade das sementes para o armazenamento (6\% a 8\%) (Mumford \& Panggabean, 1982). Desta forma, existe um nível crítico de umidade para cada espécie, que precisa ser melhor estudado, no qual o conteúdo de água é suficiente para proporcionar as reações metabólicas essenciais à manutenção da viabilidade das sementes e para evitar o desenvolvimento de microrganismos.

Em geral, durante o armazenamento, as sementes apresentaram um progressivo ressecamento do tegumento, que passou a apresentar trincas, havendo desprendimento do embrião ao se remover o tegumento, principalmente naquelas armazenadas em dessecador. Esses sintomas são evidências da perda de umidade pelas sementes. Esse comportamento aconteceu somente nos últimos meses das sementes armazenadas em câmara fria. As sementes com essas características apodreceram durante o teste de germinação.

Os resultados obtidos permitiram ampliar o tempo de armazenamento de sementes de 'Trifoliata', porém, existe a necessidade de maiores estudos nessa linha de pesquisa, principalmente no que se refere ao estabelecimento de níveis de tolerância das sementes à perda de umidade e à baixa temperatura.

\section{CONCLUSÕES}

1) Não há efeito do pré-tratamento térmico na conservação das sementes.

2)As sementes devem ser armazenadas em câmara fria.

\section{REFERÊNCIASBIBLIOGRÁFICAS}

AGRIANUAL 2003: anuário da agricultura brasileira. São Paulo: FNP Consultoria \& AgroInformativos, 2003. 544p.
BARBEDO, C.J.; BILIA, D.A.C. Evolution of research on recalcitrant seeds. Scientia agricola, Piracicaba, v.55, p.121-125, 1998.

BUTTON, J.; BORNMAN, C.H.; HACKLAND, B.A. Effect of some presowing treatments on the germination of Poncirus trifoliata and Troyer citrange seeds. Citrus and Sub-tropical Fruit Journal, Johannesburg, v.451, p.9-11, 1971.

CASTLE, W.S. Citrus rootstocks. In: ROM, R.C.; CARLSON, R.F. (Ed.). Rootstocks for fruit crops. New York: Wiley, 1987. p.361-399.

ESHUYS, W.A. Loss of viability of citrus and Poncirus trifoliata seed during storage. Citrus and Sub-tropical Fruit Journal, Johannesburg, v.489, p.5-7, 1974.

KOLLER, O.L.; STUKER, H.; VERONA, L.A.F.; SOPRANO, E. Efeito da umidade da semente, da temperatura de estocagem e da duração de estocagem sobre a germinação de Poncirus trifoliata e de outros porta-enxertos de citros. Revista Brasileira de Fruticultura, Cruz das Almas, v.15, n.1, p.27-33, 1993.

MUMFORD, P.M.; PANGGABEAN, G. A comparison of the effects of dry storage on seeds of citrus species. Seed Science and Technology, Zurich, v.10, n.2, p.257-266, 1982.

NAKAGAWA, Y.; HONJO, H. Studies on the freezing hardness and drought tolerance of citrus seeds. Bulletin of the Fruit Tree Research Station, Series A, n.6, p.27-35, 1979.

OLIVEIRA, R.P.; SCIVITTARO, W.B.; BORGES, R.S.; NAKASU, B.H. Mudas de citros. Pelotas: Embrapa Clima Temperado, 2001. 32p. (Sistemas de produção, 1).

PLATT, R.G.; OPITZ, K.W. The propagation of citrus. In: REUTHER, W. (Ed.). The citrus industry. Berkeley: University of California, 1973. v.3, p.1-47.

SAIPARI, E.; GOSWAMI, A.M.; DADLANI, M. Effect of seed drying on germination behavior in citrus. Scientia Horticulturae, Amsterdam, v.73, p.185-190, 1998.

SECRETARIA DA AGRICULTURA E DO ABASTECIMENTO. Departamento de Produção Vegetal. Comissão Estadual de Sementes e Mudas do Estado do Rio Grande do Sul. Normas e padrões de produção de mudas de fruteiras para o Estado do Rio Grande do Sul. Porto Alegre, 1998. 100p. 